Est Ag 45 (2010) 323-328

\title{
Derroteros y "tornaviaje" de Andrés de Urdaneta
}

El navegante portugués Bartolomé Díaz pasa el Cabo de Buena Esperanza y el año 1487 está en Oriente. Las mercancías e informaciones que trae interesan a mercaderes y al rey.

Años después, Cristobal Colón, marino, «profeta» y con aspiraciones de liberar «la casa Santa», ofrece al Trono de Castilla -León tesoros a los que se llega navegando al oeste- Poniente de las Islas Canarias y, con el debido permiso real, descubre «islas y tierra firme de las Indias» o «nuevo mundo».

Tales descubrimientos cambian el contenido de Tratados ${ }^{1}$. Por ello las Partes acuden al arbitraje del $\mathrm{Papa}^{2}$ y con el fin de acordar detalles las Coronas ponen el asunto en manos de expertos. De la negociación nace el «Tratado de Tordesillas 3 .

1 Por el Tratado de Alcáçovas, 4 de septiembre de 1479, Castilla recibe las Islas Canarias y es del Reino de Portugal «todo lo que es hallado o se hallare, conquistase o descubriese en los dichos términos (Madeira, Azores, Cabo Verde, Guinea), allende de que es ocupado o descubierto»

2 Alejandro VI publica dos Bulas «Inter Caetera ». De tierras y mares, 100 leguas al oeste de las Azores y Cabo Verde, pertenecerán a la Corona de Castilla. La parte oriental será de Portugal.

3 «Tratado de Tordesillas» firmado el 7 de junio de 1594 y ratificado por los Reyes Católicos en Arévalo el 2 de julio de 1494. Don Juan II lo ratidfica el 5 de sept. en Setubal. La demarcación pontificia cambia, ya que sería de Portugal cuanto se encontrase 370 leguas al oeste de las islas de Cabo Verde y, por consiguiente su autoridad se extiende hasta el $46^{\circ} 37^{\prime}$. En el texto se lee: «Y que todo lo que hasta aquí tenga hallado y descubierto y de aquí adelante se hubiese y descubriese por el dicho señor rey de Portugal y por sus navíos, así islas como tierra firme, desde la dicha raya arriba, dada en la forma susodicha, yendo por dicha parte de levante, dentro de la dicha raya a la parte de levante, o de norte o de sur de ella, tanto que sea atravesando la dicha raya, que esto sea y quede, pertenezca al dicho señor rey de Portugal y a sus sucesores para siempre jamás. Y todo lo otro... que todo sea y quede y pertenezca a los dichos señores rey y reina de Castilla y de León... y a sus sucesores para siempre jamás». La versión portuguesa está en el Archivo General de Indias. Referencia: ES 41091. 
Navegantes portugueses, con el permiso de su Rey y capital de financieros y comerciantes, desde los años $1498,1509,1510,1511,1513$ y 1514, llegando a Oriente, se instalan en Goa, Malaca y Macao. Hechos como el descubrimiento del «Gran Golfo» = Océano Pacífico por Nuñez de Balboa el año 1513 ; la entrada en México de Hernán Cortés el año 1519; el paso de un Oceano al otro por Fernando Magallanes, matado en Mactan, isla de Cebú el año 1521; la llegada de Juan Sebastian Elcano en la nave Vitoria a San Lucar de Barrameda el 6 de nov. de 1522 que le convierte en el primer hombre que da la vuelta al mundo y a quien Carlos I permite poner en sus armas el lema: «primus circumdedisti me», favorecen el «acrecentamiento de su patrimonio y corona real de Castilla» y «servicio de Dios».

Derrotero de Frey García de Loaysa, Juan Sebastian Elcano, Andrés de Urdaneta 4 :

Andrés de Urdaneta nacido en Villafranca de Oria el año 1508? escribe: «Julio de 1525 años sale (una especidión) de Coruña para las yslas de Maluco donde nasçe el clavo (especie aromática)... Guiaba el Comendador Fray García de Loaysa... Juan Sebastian Elcano natural de la Villa Guitaria (Getería) (era) Capitán de la segunda nao nombrada Santi Spiritus...

Miércoles 2 de agosto en Gomera (Islas Canarias)... comenzamos a hazer camino al sur para yr por el Estrecho de Magallanes» 5 .

Selección de documentos de AGI, 1 N. 1. La versión española se conserva en el Arquivo Nacional de Torre do Tombo. Referencia : Portugal. Torre do Tombo, Gaveta 17, mc, 2, doc. 24. (PT-TT-GAV/17/2/24).

Los barcos castellanos estaban autorizados a atravesar territorio portugués a su vuelta. El Papa Alejandro VI no confirmó este «Tratado» ; sin embargo sí lo hizo el Papa Julio II por medio de la Bula «Ea quae pro bono pacis » publicada el 24 de enero 1506. (Arquivo Nacional da Torre do Tombo. Lisboa, Bulas).

${ }^{4}$ La fuente principal que utilizo para presentar este derrotero es el documento: «Relación de los sucesos de la armada del comendador García de Loaisa desde 24 de Julio de 1525 hasta el año 1535». (Real Biblioteca, Madrid. Palacio Real. Patrimonio Nacional. Autor: Andrés de Urdaneta. Signatura: II- 1465). (Microfilmado en Madrid, año 1991). Este documento tiene 76 folios recto y verso. Los primeros 16 folios contienen narraciones de navegantes perdidos, hambrientos, sedientos, enfermos y entre «tormentas desaforadas» (fol. 5), casi desesperados, aunque con alguna esperanza en Dios, viven esperando la muerte por islas «Hayti », Jamaica ... Urdaneta ve y asiste a parte de las tragedias que describe. Algunas se las cuenta el conquistador Alvarado. Desde el folio 17 al 75 es una «Relación de Andrés de Urdaneta... fraile de... S. Agustin».

El documento de la Real Biblioteca se parece a la «Relación escrita y presentada al Emperador por Andrés de Urdaneta de los sucesos de la armada del Comendador Loaisa, desde 24 de 1525 hasta el año 1535 » firmada por el mismo Andrés de Urdaneta en Valladolid el 26 de febreo de 1537 (Archivo General de Indias. Sevilla. A :G :I. Patronato, 36. R.37).

5 Fol. 17 recto. 
El 12 enero 1526 navegan por el rio Santa Cruz (Patagonia), padecen sed, «solo me remediara con mis orines y así lo hice”. El 21 de enero observan a «patagones». «Eran indios de los quales trajeron uno el qual era muy grande cuerpo... el qual traía vestido un pellejo de zebra... y en la cabeza traía una plumas blancas de ave» ${ }^{6}$. Atravesado con mil cuitas el Estrecho de Magallanes se encuentran con las «once mil vírgenes» (Islas de Santa Inés?). Entrados «a la mar larga» los piojos les atacan. Cerca del Puerto San Jorge (Ecuador, provincia Güayas) mueren Diego de Cobarrubias, Frey Lope de Loaysa, Rodrigo Bermejo y el «lunes a seis dias de agosto falleció el manífico señor Sebatian del Cano»7.

«A quatro días del mes de setiembre...vimos tierra y era una de las islas de los Ladrones» (Marianas). Hacia ellos acude un marinero natural de Vigo quien había formado parte de los desilusionados en la espedición de Magallanes. Muere el capitan Toribio Alonso de Salazar, toma el mando Martín Iñiguez de Carquizano a quien sucede Hernando de la Torre. Procuran navegar hacia «Cebua» pero el viento les «lleva a Moluco».

Los portugueses, instalados en la fortaleza de Temate, son informados de la presencia de los españoles y tanto De Brito como Don Gorge de Meneses les notifican que aquellas tierras les pertenecen. Unos y otros procuran atraer a su bando a señores de diferentes islas e incluso luchan entre sí. A las costas de Mindanao y Malucos desde Nueva España llega Don Alvaro Saavedra Cerón. Sin embargo, las disensiones con los portugueses en Tidore, Gilolo... no cesan. Urdaneta es enviado por el capitan Hernando de la Torre a dialogar con Don Gonzalo Pereyra y, en tales circunstancias, « teníamos noticia que S. M. había empeñado las dichas yslas y a las Molocas al Rey de Portugal lo qual teniamos pensado de nos yr de las dichas yslas para España» 8 . «Al fin de febrero de 1525 -cuenta Urdaneta- parti de las yslas Moloca para la India de Portugal». El 25 de junio de 1536, Urdaneta, acompañado de su hija y consciente que es el segundo hombre en dar la vuelta al mundo, entra en Lisboa.

6 Fol. 20 recto

${ }^{7}$ Fol. 26r.

${ }^{8}$ Fols. 71 verso y 72 recto. El Tratado de Zaragoza es firmado el 22 de abril 1529 por expertos de Carlos I de España y Juan III de Portugal. España vende a Portugal «todo derecho, acción, dominio, propiedad, posesión o casi posesión y de todo derecho a navegar, contratar y comerciar en el Maluco, por 350.000 ducados de oro, de 375 maravedises cada uno» (Arquivo Nacional da Torre do Tombo, Lisboa. Gaveta 18, maço 8, $\mathrm{n}^{\circ} 29$ ). 
Derrotero de Fray Andrés de Urdaneta con Miguel López de Legazpi y «tornaviaje» 9 :

A. de Urdaneta en compañía de Pedro Alvarado e interesados se informan, informan y contratan en la Casa de Contratación de Sevilla. Con proyectos acordados llegan a Santo Domingo. Alvarado muere. Urdaneta en Nueva España continúa dialogando sobre lo que ha visto y conoce. Con amigos examinan las expediciones y fracasos de Grijalba, año 1536; de Villalobos, año 1542 ; de la Torre, año 1543 e Íñigo Ortiz de Retes, año 1545. Urdaneta conoce a los agustinos favorecidos por un hermano de Alvarado, gobernador en Michoacan y padre de un agustino quien con los PP. de San Román, Aloso de Veracruz y Alonso Gutierrez, defensor de Copérnico y Rethius en la obra «Physica Speculatio», fundan el Colegio Mayor de Tiripetio donde, entre otras cosas, se enseñan las matemáticas y cosmografía. Andrés de Urdaneta el año 1552 profesa en la Orden de San Agustín ${ }^{10}$. Dialoga con el Virrey Luis de Velasco y tanto insiste sobre la posibilidad de volver desde Filipinas que el P. Esteban de Salazar comenta: «Prometía con tanta deliberación la buelta de Filipinas a la Nueva España, que con ser hombre modestísimo en hablar, solía decir que él haría volver no una nave, sino una carreta». Tal afirmación contrasta con la del misionero Francisco Javier, quien desde India escribía a un hermano de la Orden: «No manden más armadas por via de Nueva España a descubrir las Islas Pláteas... los navíos no tienen ninguna salvación».

Sucesos favorecen se pida ayuda a Fray Urdaneta. Felipe II, año 1556, es Rey de España y con el fin de afixiar el Imperio Otomano, pagar gastos y preparar viajes a China, necesita capital, aumentar el control sobre los mercados de la especería y volver con las mercancías a Nueva España. El

9 Sin olvidar otras fuentes consulto: Mss. P. Goyangos. Actualmente Biblioteca de Inglaterra. Londres. Add.28.189. paper, small 4 to. ff. 8. XVI. Cent. En la relación de viajes están:

3. «Principio y relación y derrotero de Estevan Rodriguez piloto del descubrimiento de las yslas del Poniente.

4. Derrotero del piloto Rodrigo de Espinosa de la vuelta de las yslas del Poniente» Add. 9944. paper. In folio ff. 306. XVI. cent

El P. Isacio Rodríguez y su colosal obra: «Historia de la Provincia Agustiniana del Santísimo Nombre de Jesús de Filipinas» es un referente. Importante es la conferencia del P. Sierra sobre «Urdaneta y el «Tornaviaje» y digna de elogio es la publicación: AA.VV «Descubrimientos españoles en el Mar del Sur».

10 En la Orden de San Agustín profesan: Mendel, Lutero, Erasmus, Urdaneta, Fray Luis de León, P. Flórez... 
Virrey notifica la «experiencia» de Urdaneta quien es «el mejor e más cierto cosmógrafo», «el que ha de gobernar y guiar la jornada»... El Virrey muere y con el mandato de la Audiencia, el 21 de noviembre de 1564 desde el Puerto de Navidad, con Legazpi como Capitan general y Urdaneta en calidad de guía, comienza el derrotero de capitanes, marineros y agustinos en los Galeones San Pedro y San Pablo y Pataches San Juan y San Lucas. Rumbo hacia Flipinas pasan al sur de las Islas Hawaii, descubren las islas «Barbados» = Mejit, «Los Placeres» = Ailuk, «Los Pájaros» = Jemo, «Hermanas»= Aotho y el 23 de enero 1565, llegados a la Isla Los Ladrones y Guam, Legazpi pronuncia la fórmula de posesión en nombre del Rey y Urdaneta celebra Misa. El 13 de febrero dificultosamente comienzan a abrir negociaciones y ganar espacio en las islas Samar y Cebú en Filipinas. El 16 de mayo en una casa se encuentra el «Niño Jesús de Cebú», que se convierte en signo de unión entre Filipinas y España.

\section{«Tornaviaje»}

Legazpi queda en Cebú. Felipe Salgado es el nuevo Capitán. El 1 de Junio salen de Cebú y por el estrecho San Bernardino entran en el Oceano. A la derecha dejan «Parece Vela». Ascienden a $29^{\circ}$ y a las corrientes KouroChivo, el 3 de agosto llegan a los $39^{\circ} 30$ y el 18 septiembre 1565 Rodrigo Espinosa comenta: "Pareció al padre prior y a mi que fuésemos gobernando al oeste porque conforme a una figura que él traía estaban estas islas cerca de tierra firme (California)». Están ante la isla Deseada=¿Isla San Miguel? desde donde descienden a la Isla Cedros. En el Puerto de Navidad les notifican que Alonso Arellano, desertor con el Petache San Lucas, empujado por las corrientes, hacía dos meses que había entrado en el Puerto. El año 1592 el P. Gaspar de San Agustín nota: «Llegando al Puerto de Acapulco -8 oct.- pintó Urdaneta la carta con todos los vientos y derroteros, puntos y cabos tan cumplidamente que es su carta la que hoy se sigue, sin haberle añadido cosa alguna».

\section{Conclusiones}

Hasta el año 1815 el Galeón Acapulco-Manila o Nao de China navegó de manera continua.

Oriente, América y Europa se beneficiaron y benefician del esfuerzo y ciencia de Andrés de Urdaneta. 


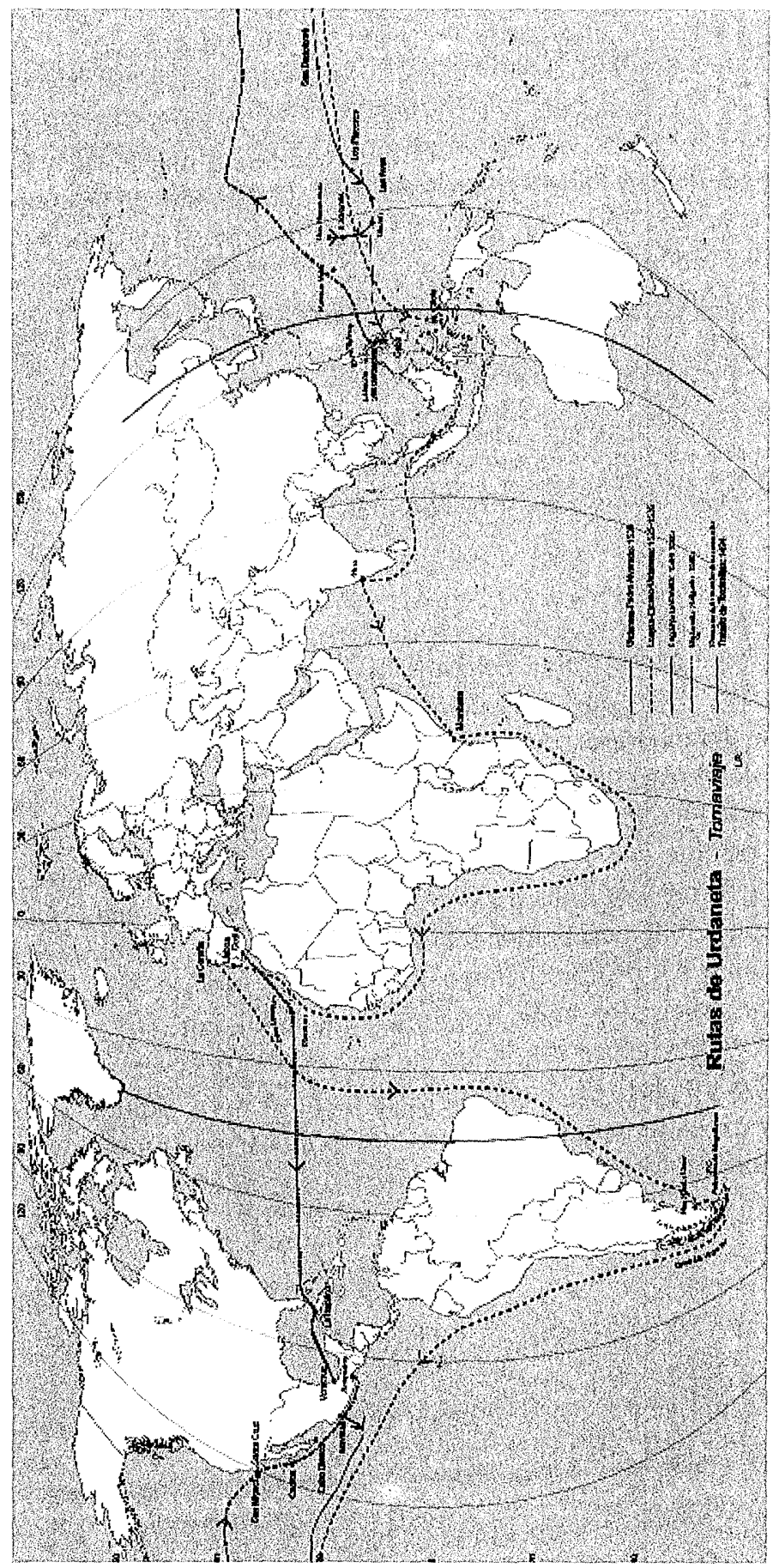

